\title{
Leitura em voz alta e discussões orais: estratégias de ensino nas aulas de Língua Portuguesa
}

\author{
Márcia Andréa Almeida de Oliveira ${ }^{1}$ \\ Alessandra Karina Gomes de Araújo ${ }^{2}$
}

\begin{abstract}
RESUMO
Neste artigo, discute-se o efeito das instruções de leitura nas aulas de Língua Portuguesa. Com base nos estudos sobre leitura, bem como nas pesquisas qualitativa e documental e na análise de conteúdo, buscamos verificar os tipos de instrução que foram usados nas aulas ministradas por uma estagiária e com que frequência cada um foi mobilizado, bem como a relação entre eles e o engajamento dos alunos nas atividades e a quantidade de questionamentos que fizeram. Os resultados revelam que quanto mais leitura em voz alta e discussão oral sobre o texto maior é o engajamento dos alunos do $9^{\circ}$ do Ensino Fundamental e menor a quantidade de dúvidas por eles demonstradas. O estudo também evidenciou que na prática de leitura silenciosa eles mostraram compreender menos os textos lidos em sala de aula.
\end{abstract}

PALAVRAS-CHAVE: Compreensão Leitora. Instrução de Leitura. Leitura em Voz Alta. Discussão Oral. Leitura Silenciosa.

Reading aloud and oral discussion: instruction strategies in Portuguese Language class

\begin{abstract}
In this article, we discuss the effect of reading teaching in Portuguese language classes. Based on reading studies, as well as qualitative and documentary research and content analysis, we sought to verify the types
\end{abstract}

\footnotetext{
${ }^{1}$ Doutora em Linguística Aplicada. Universidade Federal do Pará, Belém, Pará, Brasil. https://orcid.org/0000-00028214-7908.andrea.almeida.oliveira@gmail.com.

${ }^{2}$ Graduada em Letras. Universidade Federal do Pará, Belém, Pará, Brasil. https://orcid.org/0000-0002-7838-6738. alessandrakarinabrito@gmail.com.
} 
of instruction that were used by a trainee to teach reading, and how often she set each one. We also aim to identify the relationship between them and the students' engagement in the activities and the number of questions they asked. The results show that the more reading aloud and oral discussion about the text the higher is the engagement of the students attending $9^{\text {th }}$ grade, and the lower is the number of questions. The study also showed that in the practice of silent reading they seemed to do not understand the texts read in the classroom.

KEYWORDS: Reading Comprehension. Reading Instruction. Reading Aloud. Oral Discussion. Silent Reading.$$
* * *
$$ \\ Learning to read and write ought to be one of the most joyful and successful of \\ human undertakings. \\ Don Holdaway
}

\title{
Introdução
}

A partir da década de 1980 no Brasil, ganha expressividade a discussão de que ler não é somente decifrar sinais gráficos e de que a aprendizagem de leitura não está associada unicamente à alfabetização. Ainda hoje, é frequente a atribuição de problemas de leitura dos alunos ao professor dos três primeiros anos. Ressalte-se que a aprendizagem da leitura deve desenvolver-se durante a Educação Básica e para além desta, sendo, portanto, de responsabilidade de todos os professores, não só os de Língua Portuguesa.

Conforme Shanahan e Shanahan (2008) descrevem, o desenvolvimento do letramento envolve três níveis: letramento básico, letramento intermediário e letramento disciplinar ${ }^{3}$. Isso evidencia que os alunos precisam desenvolver habilidades específicas conforme a área de

\footnotetext{
3 “Letramento básico: habilidades de letramento, como decodificação e conhecimento de palavras mais frequentemente usadas, as quais são subjacentes a praticamente todas as tarefas de leitura.

Letramento intermediário: habilidades de letramento recorrentes em muitas tarefas, incluindo estratégias genéricas de compreensão, significados de palavras comuns e fluência básica.

Letramento disciplinar: habilidades de letramento específicas à história, ciência, matemática, literatura ou outra disciplina" (FISHER; FREY, 2015, p. 151).
} 
conhecimento; por isso, é necessário que haja a participação de todos os docentes nesse processo.

Com base nos artigos lidos sobre o tema abordado, percebemos que eles versam mais frequentemente acerca do ensino de leitura na escola, em que se discutem as práticas existentes ou se analisam intervenções realizadas em diferentes níveis da Educação Básica (OLIVEIRA, 2003, ALVES, 2012, TASSONI; RIBEIRO, 2013, CAMILO, 2015, BARRETO; GUIMARÃES, 2015, ANGELO; MENEGASSI, 2016, GOMES, 2017, DANIA, 2018), bem como de concepções de ensino e estratégias de leitura (KLEIMAN, 1992, SILVA, 1999, RODRIGUES, 2007; FUZA; OHUSCHI; MENEGASSI, 2011, MENEGASSI, 2010, PANICHELLA, 2015, PEREIRA; SANTOS, 2017). O estudo aqui proposto se diferencia na medida em que descreve e analisa aulas de leitura, mediadas por sequências didáticas, focando nas instruções mobilizadas para ensinar os alunos a ler.

Para desenvolver a pesquisa, cujos resultados são aqui apresentados, baseamo-nos nos estudos sobre concepção de leitura (SOLÉ, 1998, ANTUNES, 2003, KOCH; ELIAS, 2014) e instrução de leitura (DUKE; MARTIN, 2015, GAMBRELL; MORROW, 2015, MURPHY et al., 2009, FOUNTAS; PINNELL, 2006), bem como nas pesquisas qualitativa e documental (GODOY, 1995) e na análise de conteúdo (GOMES, 1994, PÁDUA, 2002). Destarte, procuramos responder às seguintes perguntas: (i) Que tipos de instrução foram usados para ensinar leitura e com que frequência cada um foi mobilizado?; (ii) Qual é a relação entre o tipo de instrução e o engajamento dos alunos nas atividades?; e (iii) Qual é a relação entre o tipo de instrução e a demonstração de dúvidas pelos alunos?.

Conscientes do papel das ações do professor na aprendizagem da leitura, analisamos o fazer docente de uma estagiária em uma turma de Língua Portuguesa (língua materna), no tocante ao uso de instruções de leitura, buscando relacioná-las ao engajamento dos alunos, do $9^{\circ}$ do Ensino Fundamental II, de escolas públicas da cidade de Belém, e à quantidade de dúvidas por eles demonstradas. 
A seleção do ano escolar ocorreu em função dos resultados do Sistema de Avaliação da Educação Básica (Saeb/2017), os quais mostram que os alunos do Pará alcançaram, no Ensino Fundamental - anos finais, 233,39 em leitura, índice abaixo da média nacional, que é 251,68. Esses resultados revelam também que 65,94 desses estudantes não alcançaram o nível 4, em uma escala de proficiência que contém nove níveis, apontando um desenvolvimento rudimentar da compreensão leitora ${ }^{4}$.

A fim de direcionar a discussão em torno do tema da pesquisa, primeiramente, tratamos das concepções e tipos de instrução de leitura; depois, apresentamos os procedimentos metodológicos adotados; e, por último, discorremos a respeito dos resultados da pesquisa, buscando responder às perguntas propostas.

\section{Leitura e tipos de instrução}

Existem diferentes formas de conceber leitura. Baseados em Antunes (2003) e Koch e Elias (2014), posicionamo-nos a favor da concepção sociocognitiva e interativa de leitura. Segundo essa visão, o sentido não está no autor ou no leitor, mas é construído na interação entre leitor, texto e autor. A leitura é "[...] uma atividade na qual se leva em conta as experiências e conhecimentos do leitor [...]", bem como "[...] exige do leitor bem mais que o conhecimento do código linguístico, uma vez o texto não é simples produto da codificação de um emissor a ser decodificado por um receptor passivo" (KOCH; ELIAS, 2014, p. 11).

De acordo com Antunes (2003), o ato de ler pressupõe a definição de objetivos. Acerca disso, Solé (1998, p. 22) destaca que podemos ler com vários propósitos, por exemplo, para: "[...] desvanear, preencher um momento de lazer e desfrutar; procurar uma informação concreta; seguir uma pauta ou instruções para realizar uma determinada atividade [...]; informar-se sobre

\footnotetext{
${ }^{4}$ Para mais informação sobre o Saeb, consultar 〈http://portal.inep.gov.br/educacao-basica/saeb〉.
} 
um determinado fato [...]”, entre outros. Os objetivos são, portanto, diferentes à medida que as situações de leitura também mudam.

Ler um texto significa perceber o contexto histórico, social, econômico, filosófico e político em que ele se insere, significa reconhecer a finalidade do texto, a posição do autor e o possível leitor (ANTUNES, 2003). Por intermédio da leitura, os alunos podem ampliar seu conhecimento sobre diferentes textos de diferentes gêneros e podem ter acesso a informações e saberes de diversas áreas do conhecimento humano. Nesse sentido, Kintsch e Kintsch (2005) afirmam que, em contexto educacional, o objetivo é aprender a partir do texto, mas essa tarefa não é tão simples, porque envolve um processo ativo de produção de sentidos, o qual requer a mobilização de diferentes conhecimentos e de estratégias de leitura.

Antunes (2003) ressalta que usamos diferentes estratégias para ler conforme os gêneros de texto, porquanto não lemos da mesma maneira, por exemplo, um artigo de opinião e um conto de terror. A esse respeito, Duke e Martin (2015, p. 250, tradução nossa) afirmam que

[...] os processos envolvidos na compreensão de um gênero não são isomórficos com aqueles envolvidos no entendimento de outros; a habilidade de compreender bem um não garante a compreensão de outros. O propósito e as características do gênero influenciam nos processos envolvidos em compreendê-lo eficazmente.

Solé (1998, p. 69) ressalta que não se trata de ensinar receitas para os alunos, até mesmo pelo fato de que as estratégias “[...] não detalham nem prescrevem totalmente o curso de uma ação [...]”. De acordo com Fang (2012), na abordagem cognitiva, as estratégias, como predição, monitoração e sumarização, colaboram para o desenvolvimento da leitura dos alunos, sendo mais efetivo para aprendizagem quando essas são ensinadas em conjunto e não isoladamente. 
Diferentes estratégias podem ser mobilizadas antes, durante e depois da leitura. Antes da leitura de um texto, por exemplo, podemos atentar inicialmente para o título e subtítulo e, a partir deles, prever de qual assunto o texto tratará. Esses indicadores servem para ativar o conhecimento prévio que, por sua vez, vai auxiliar no processo de predição (MENEGASSI, 2010). Durante a leitura, podemos nos autoquestionar ao final de cada parágrafo e refletir sobre o que foi lido, de modo a monitorar a nossa compreensão do texto, podemos elaborar hipóteses sobre o sentido e prever o que será dito adiante etc. Depois da leitura, podemos sintetizar o texto, a fim de destacar a ideia principal, reorganizando as informações na ordem em que foram apresentadas pelo autor, entre outras estratégias que podem ser empregadas nesse momento (SOLÉ, 1998).

O ensino de leitura, portanto, requer do professor o reconhecimento da importância da leitura na construção de cidadãos capazes de ler para fruir e ler para aprender etc., dos conhecimentos envolvidos na atividade de ler e do papel das estratégias. Exige ainda a consciência de que o desenvolvimento da compreensão leitora pressupõe instruções de leitura, que consistem em ajudar os alunos a se tornar leitores autônomos, capazes de lançar mão de diferentes estratégias para controlar e desenvolver a compreensão dos textos, por meio do ensino explícito e contínuo, conduzido pelo professor a respeito dos diferentes saberes relacionados a essa prática (GAMBRELL; MORROW, 2015).

De acordo com Duke e Martin (2015), ao ensinar leitura, podemos lançar mão de diferentes modos de instrução, a saber: ler em voz alta, propor discussão, atividades de pré-leitura e ajuda visual. Para nosso objetivo de pesquisa, discorreremos, neste artigo, apenas sobre os dois primeiros modos de instrução.

A leitura em voz alta tem um papel fundamental na aprendizagem da leitura pelos alunos (BECK; MCKEOWN, 2001, ECROYD, 1991; FISHER et al., 2004, FOUNTAS; PINNELL, 2006). Ela corresponde àquela que é feita pelo 
professor ou por um aluno em voz alta ${ }^{5}$. Por muitos anos, esse tipo de leitura possibilitou a aproximação entre os que não tinham acesso aos livros com a cultura da escrita (CHARTIER, 1994). Essa modalidade, na escola, constituise importante instrumento para aproximar os alunos da lógica da escrita, levando-os a se apropriar de algumas de suas características. Segundo Cagliari (2002, p. 156), "[...] ouvir uma leitura equivale a ler com os olhos, a única diferença reside no canal pelo qual a leitura é conduzida do texto ao cérebro".

De acordo com Fountas e Pinnell (2006), a leitura em voz alta realizada pelo professor desempenha um papel fundamental na formação de leitores, visto que ela permite aos alunos não se preocupar com a decodificação e com a pronúncia das palavras, dedicando-se mais à construção dos sentidos. Ela favorece que eles ouçam as estruturas do texto, expondo-os a uma linguagem que ainda não dominam e dando acesso a um conjunto de características que ampliarão seu uso da língua. "Quando os alunos têm a oportunidade de ouvir uma variedade de língua escrita lida em voz alta, ela torna-se acessível para eles, e esse acesso à língua é importante para os estudantes de todas as idades." (FOUNTAS; PINNELL, 2006, p. 216, tradução nossa).

Esse modo de ler permite também ao professor "[...] iniciar leitores, promover o contato com os livros, dar andamento às histórias de leitura [...]" (MEDINA; PRADES, 2015, p. 26). A leitura feita pelo docente se faz relevante ainda pelo fato de ajudar os alunos que não são autônomos no processamento do texto e porque possibilita despertar o interesse por essa atividade de linguagem.

Algo relacionado a essa modalidade é a possibilidade de ser também interativa, que consiste na leitura do texto em voz alta pelo professor e na participação dos alunos na discussão sobre o texto. Por meio da leitura em voz alta interativa, é possível proporcionar aos alunos pensar "dentro do texto",

\footnotetext{
${ }^{5}$ No ensino do inglês, é feita diferença entre instrução leitura em voz alta, leitura compartilhada e leitura fragmentada ou jogral. Para efeito de análise, no entanto, não fazemos diferença, porque parece não haver clareza quanto a esses termos pela estagiária. Então, usamos o termo leitura em voz alta para nos referir ao momento em que o professor ou aluno lê oralmente.
} 
"além do texto" e "sobre o texto" (FOUNTAS; PINNELL, 2006). Durante esse processo, o professor pode interromper a leitura para conversar sobre os sentidos do texto, levando-os a identificar importantes informações para retomar em forma de síntese, a pensar a respeito das intenções do autor, a refletir sobre o tema e a se posicionar acerca do que foi lido.

A leitura em voz alta pode ser ainda realizada pelos alunos. Por meio dela, é possível verificar se eles leem com fluência, respeitando a pronúncia das palavras, a pontuação e dando a entonação adequada. É necessário, contudo, não usar essa modalidade para avaliar a compreensão do texto lido, porque esse modo dificulta ao leitor perceber a intencionalidade do autor, a finalidade do texto etc. (SOLÉ, 1998).

Caso a oralização do texto escrito seja o foco, a autora sugere a realização da leitura silenciosa antes, pois lhes possibilita seguir o próprio ritmo, resolver problemas de compreensão, consultando dicionário ou relendo os trechos do texto, de modo que consigam interpretar o que leram. Quando não ocorre o reconhecimento prévio do texto por meio da leitura silenciosa, eles tendem a não compreender o que leem, porque "[...] a voz está sempre atrás da compreensão, e é sempre suscetível, até certo ponto, de divergir do texto real" (SMITH,1989, p. 191).

Por experiência, sabemos que ao ler alto, em público, ansiosos por uma boa "performance" deixamos na verdade de acompanhar a nossa própria leitura. Mecanicamente perseguimos a linearidade do texto. E somos mais felizes na leitura oral, principalmente em "expressividade" quando lemos anteriormente o texto, e o lemos silenciosamente. Porque a expressividade da leitura é comprometida pela linearidade. Ela é dada pelo conjunto todo. A prática de leitura oral compromete enfim a leitura do texto, se entendemos que ler é mais do que decifrar e recitar sinais. (SILVA, 1985, p. 19). 
Destarte, a leitura em voz alta realizada pelos alunos precisa ser feita com cautela, para que não dificulte a atividade de compreender textos e não interfira no crescimento sócio-emocional deles.

A discussão oral igualmente desempenha um importante papel no desenvolvimento da compreensão leitora (DUKE; MARTIN, 2015, MURPHY et al., 2009, LUCAN; HAPGOOD; PALINCSAR, 2011). Essa visão deriva das teorias sociocognitiva e sociocultural, sustentadas em Piaget e Vygotsky. Nessa perspectiva, o indivíduo desenvolve as habilidades de ler por meio da participação em ambientes letrados e por meio da interação com as pessoas em seu entorno (MURPHY et al., 2009).

Esse tipo de instrução é relevante, uma vez que

[...] a experiência verbal individual do homem toma forma e evolui sob o efeito da interação contínua e permanente com os enunciados individuais do outro. É uma experiência que se pode, em certa medida, definir como um processo de assimilação, mais ou menos criativo, das palavras do outro (e não das palavras da língua). Nossa fala, isto é, nossos enunciados (que incluem as obras literárias), estão repletos de palavras dos outros, caracterizadas, em graus variáveis, pela alteridade ou pela assimilação, caracterizadas, também em graus variáveis, por um emprego consciente e decalcado. As palavras dos outros introduzem sua própria expressividade, seu tom valorativo, que assimilamos, reestruturamos, modificamos. (BAKHTIN, 1997, p. 313-124, grifos do autor).

Vale ressaltar que a discussão a que nos referimos é aquela que toma como base um texto. A partir deste, os alunos têm a oportunidade de trazer para as discussões seus valores sociais e culturais e suas experiências prévias e, por meio delas, confirmar, negociar, sustentar e/ou modificar sua interpretação e sua visão de mundo (PIERCE; GILLES, 2008). 
Ainda em relação às discussões em sala de aula, a qualidade das discussões está relacionada à habilidade de os alunos resolverem problemas, compreenderem textos e aprenderem diferentes conhecimentos (MERCER; DAWES, 2008). Com base nisso, podemos dizer que a discussão oral é crucial para a compreensão do texto, não se tratando apenas de um meio para eles mostrarem o que sabem ou não, mas também é um momento em que "[...] interrogam o texto em busca de argumentos, suposições, visões de mundo ou crenças que podem ser inferidas a partir dele" (SOTER et al., 2008, p. 374, tradução nossa).

Com base nesses estudos, reconhecemos que a compreensão do texto pode ser fomentada por meio da leitura em voz alta e da discussão oral sobre o texto.

\section{Metodologia}

A pesquisa é de abordagem qualitativa (GODOY, 1995), pois buscamos descrever e analisar os modos de instrução acionados por uma estagiária ao longo de 12 horas-aula, ministradas no ano de 2018.

Sobre os procedimentos, realizamos uma pesquisa bibliográfica, a fim de conhecer o que já existia sobre o tema. Recorremos ainda à pesquisa documental (HELDER, 2006), porquanto realizamos análise de notas de campo, escrita pela estagiária participante da pesquisa. Nos relatos das aulas, ela descreve as situações de ensino vivenciadas em uma turma do $9^{\circ}$ ano do Ensino Fundamental II para a qual ensinou leitura, usando como material de apoio uma sequência didática, fundamentanda no gênero conto de terror e em estratégias de leitura.

Para tratar e analisar os dados, fizemos uso da análise de conteúdo. De acordo com Gomes (1994, p. 74), por meio desse método, “[...] podemos encontrar respostas para as questões formuladas [...]", confirmar as hipóteses e descobrir o "[...] que está por trás dos conteúdos manifestos [...]". A análise de conteúdo desenvolve-se em três fases: pré-análise, exploração do material 
e tratamento dos dados e interpretação. A primeira fase envolve a escolha dos documentos e a formulação de hipóteses. A segunda inclui a codificação, isto é, a escolha das categorias que vão direcionar o olhar sobre o texto (notas de campo). A terceira abrange procedimentos estatísticos e generalização ou não do que foi observado a partir dos dados (PÁDUA, 2002).

O estudo aqui apresentado foi realizado em uma escola estadual de Ensino Fundamental e Médio, localizada em um bairro de classe baixa do munícipio de Belém (PA). Está atrelado a uma pesquisa de natureza experimental, que tinha como finalidade a implementação de sequências didáticas de leitura (dispositivo de ensino ainda em construção) para verificar de que modo elas podem promover o ensino de leitura por meio de estratégias e a avaliação da compreensão leitora (aspectos esses desenvolvidos em outros artigos).

Da pesquisa, participaram 35 alunos, com em média 15 anos; todos provenientes de famílias em condição socioeconômica desprestigiada. As aulas foram ministradas por uma estagiária do curso de Letras (Licenciatura Língua Portuguesa) da Universidade Federal do Pará (Campus Belém).

A sequência didática de leitura elaborada pela estagiária estava estruturada em seis etapas, como mostrado no quadro 1.

QUADRO 1: Estrutura da sequência didática de leitura

\begin{tabular}{|l|l|}
\hline \multicolumn{1}{|c|}{ Etapas } & \multicolumn{1}{|c|}{ Finalidades } \\
\hline Etapa 1 & $\begin{array}{l}\text { Dedicada à introdução ao gênero, visava à apresentação dos } \\
\text { elementos da situação de comunicação do gênero, seu } \\
\text { conteúdo temático e sua estrutura composicional. }\end{array}$ \\
\hline Etapas 2 e 6 & $\begin{array}{l}\text { Destinadas à verificação das habilidades de leitura já } \\
\text { desenvolvidas e do conhecimento sobre o gênero em estudo. }\end{array}$ \\
\hline $\begin{array}{l}\text { Etapas 3, 4 e } \\
5\end{array}$ & $\begin{array}{l}\text { Voltadas ao trabalho com estratégias de leitura mobilizadas } \\
\text { antes, durante e depois da leitura: predição, } \\
\text { autointerrogação e sumarização. }\end{array}$ \\
\hline
\end{tabular}

Fonte: as autoras.

Para a análise, não usamos a segunda e a última etapas da sequência, porque essas tinham o objetivo de avaliar a aprendizagem dos alunos, em um momento separado das ações de ensinar. 
Para o tratamento das informações presentes nas notas de campo, inicialmente, fizemos uma leitura geral do material e definimos duas hipóteses: (i) Nas aulas em que predominou leitura silenciosa, os alunos demonstram mais compreensão do texto; e (ii) Os alunos mostram-se mais engajados nas aulas em que houve discussão oral sobre o texto. Depois, selecionamos algumas categorias de análise, tendo como base o referencial teórico adotado e o que observamos na primeira leitura das notas de campo, a saber: leitura em voz alta, leitura silenciosa e discussão oral sobre o texto. Por último, interpretamos como as instruções leitura em voz alta e discussão oral sobre o texto relacionavam-se com o nível de engajamento dos alunos e com a quantidade de questionamentos que faziam acerca do texto ou do comando das atividades.

\section{Modos de instrução: leitura em voz alta e discussão oral sobre o texto}

Ao longo da realização da sequência didática, a estagiária utilizou diferentes modos de instrução, como: leitura em voz alta, leitura silenciosa e discussão oral sobre o texto. Após identificarmos esses tipos de instrução, relacionamos essas formas de ensinar ao engajamento dos alunos nas atividades e à quantidade de questionamentos que fizeram ao longo de cada etapa da sequência didática.

\section{Leitura em voz alta}

Sabemos, de acordo com a revisão da literatura, que a leitura em voz alta e a silenciosa exercem um papel importante em sala de aula e que precisam ser acionadas de acordo com o propósito de ensino e o nível de desenvolvimento dos alunos.

Observamos que não houve diferença significativa entre um ou outro modo de ler nas aulas da estagiária. Dos 15 textos usados nas aulas, nove foram lidos em voz alta e seis, silenciosamente. 
A leitura em voz alta, como destacam Duke e Martin (2015, p. 256, tradução nossa), "[...] pode ajudar os alunos a se familiarizar com a linguagem e outras características do texto, a compreender como adultos e seus pares pensam sobre o texto, e a desenvolver conhecimento sobre o conteúdo [...]”. Considerando essa citação, esse tipo de instrução pressupõe um leitor fluente e intervenções do professor durante a leitura. Mas, não é o que ocorre nas aulas ministradas pela estagiária. Por exemplo, no caso da maioria das situações de leitura em voz alta realizadas, seis, de nove, foram feitas pelos alunos, que nem sempre eram fluentes. Além disso, apenas uma vez a estagiária parou a leitura para fazer comentários. Ela frequentemente lia ininterruptamente e, ao final, perguntava se os alunos tinham gostado ou não do texto.

A leitura em voz alta, contudo, parece ter contribuído para que os alunos fizessem menos questionamentos em relação às atividades propostas. Observamos que nos eventos de leitura em voz alta foi menor o questionamento dos alunos sobre as atividades. Esse tipo de instrução parece ter contribuído para a compreensão do texto, quando comparamos com a ocorrência de dúvidas durante a leitura silenciosa. Segundo Rasinski e Padak (2000), esse modo de instrução beneficia, especialmente, aqueles que ainda não leem bem, justamente por evidenciar aspectos relacionados à pronúncia das palavras, à entonação, à velocidade de leitura etc.

Nossas observações divergem daquelas apresentadas por autores, como Holmes (1985), ao destacar que a leitura silenciosa possibilita maior compreensão do que a leitura em voz alta. Uma hipótese para esse resultado é que, talvez, os alunos não eram autônomos na leitura; por isso, não conseguiram construir sentidos a partir dos textos lidos silenciosamente. Embora a leitura silenciosa tenha inúmeras vantagens, como favorecer "[...] uma velocidade de leitura maior, podendo ele [o leitor] parar onde quiser e recuperar passagens já lidas, o que a leitura oral não costuma permitir [...]" (CAGLIARI, 2002, p. 156), essa modalidade pode gerar dificuldades, ou mesmo, tornar a tarefa de ler inviável se os alunos, por exemplo, não 
souberem decodificar as palavras automaticamente, desconhecerem a maioria dos significados dos vocábulos do texto, não tiverem adquirido estruturas mais complexas da língua, não reconhecerem a função dos elementos coesivos, não dominarem os gêneros (fábula, poema, artigo de opinião ...) e os tipos textuais (narrativo, argumentativo, expositivo ...), e não souberem mobilizar estratégias de leitura para construir os sentidos. Os dados revelaram que, quando os alunos precisavam ler sozinhos, mostraram bastante dificuldades no que diz respeito à compreensão dos textos e dos comandos das atividades, o que talvez indique problemas de leitura.

Verificamos também que, nas aulas em que a leitura em voz alta não ocorreu com tanta frequência, o engajamento dos alunos foi menor. Desse modo, nossas observações corroboram o que Klesius e Griffith (1996) destacam sobre a leitura em voz alta: o contato com esse tipo de instrução aumenta a motivação dos alunos e contribui para a construção do conhecimento necessário para a aprendizagem da leitura. Segundo Morrison e Wlodarczyk (2009, p. 112 e 117, tradução nossa), “[...] os eventos de leitura em voz alta fornecem um contexto benéfico para os alunos perceberem como a linguagem funciona [...]" e podem "[...] servir como um trampolim para envolver os alunos em inúmeras atividades relevantes para o objetivo de aprendizado desejado".

Concordamos com Marinak e Gambrell (2008), quando afirmam que a motivação desempenha um papel central no desenvolvimento da compreensão leitora, sendo a leitura em voz alta responsável não só pelo aumento das habilidades de compreensão oral e do aperfeiçoamento da compreensão escrita, como também pela construção da motivação necessária para a aprendizagem da leitura.

Nossa análise mostra que ela contribuiu para a criação de momentos de discussão e de construção coletiva dos sentidos dos textos, estimulou o engajamento dos alunos nas atividades e diminuiu a quantidade de dúvidas sobre os textos e o comando das questões. 


\section{Discussões orais sobre o texto}

Embora as discussões do texto estivessem presentes, as perguntas feitas pela estagiária eram de compreensão global em torno do tema e de extrapolação, sem demandar que os alunos lessem o texto ou voltassem nele para melhor compreendê-lo.

Após a leitura, questionei-os se já conheciam a história lida e como tinham conhecido.

Duke e Martin (2015) relacionam a discussão sobre o texto com o desenvolvimento da compreensão dos alunos. Contudo, essas discussões precisam ser significativas, as perguntas precisam ser planejadas conforme os objetivos de leitura (FISHER; FREY, 2015). No caso das discussões realizadas, percebemos que, frequentemente, as perguntas formuladas podiam ser respondidas sem a leitura do texto.

Após a leitura, iniciei os questionamentos sobre o texto, o que tinham achado, se já haviam lido aquele texto, e muitos mencionaram um filme recente que envolve bonecas, elemento presente no texto lido.

Quando analisamos as interações entre a estagiária e os alunos, verificamos que as discussões não os desafiaram a localizar informações no texto e a refletir acerca delas, trazendo suas experiências para o momento. Por exemplo, não constam no relato falas que lhes tenham sido encaminhadas, como: "Você está dizendo que..." e "Onde isso fica evidente no texto?". Ao contrário disso, eles participaram dando a opinião a respeito de algo que foi lido e sobre se gostaram e do que gostaram no texto. Tais perguntas são importantes, mas é necessário também levá-los a identificar informações, a fazer afirmações com relação ao texto sustentando-as com aspectos linguísticos, a conectar as informações do texto com as experiências 
anteriores, a perceber os elementos que promovem relação entre as ideias etc. Os questionamentos precisam ser ancorados no texto, para que a instrução se caracterize de leitura. "Questões baseadas no texto levam os alunos a se engajar em releituras significativas e a avançar em sua compreensão indo além do nível superficial.” (FISHER; FREY, 2015, p. 158, tradução nossa).

Igualmente é possível constatar que, quando houve mais discussão oral, eles se mostraram mais participativos, corroborando o que McElhone (2012) diz a respeito dessa modalidade de instrução: a interação entre professor e alunos apoia o desempenho da compreensão dos alunos e o seu engajamento na leitura.

A falta de discussão sobre o texto influenciou diretamente o engajamento dos alunos nas atividades de compreensão leitora. Podemos dizer que essa foi prejudicada, se considerarmos que o "[...] engajamento em leitura desenvolve as habilidades de leitura, constrói vocabulário e conteúdo, e familiariza leitores com a área de conteúdo, com formas de língua específicas de uma disciplina, bem como com estruturas do discurso [...]" (GODMAN; SNOW; VAUGHN, 2016, p. 259, tradução nossa).

Houve ainda relação entre maior frequência das discussões orais e menor quantidade de dúvidas acerca do texto e dos comandos das atividades, o que demonstra ser essa instrução favorável, principalmente, para a construção de sentido pelos alunos não proficientes em leitura.

Dos 15 textos apresentados aos alunos pela estagiária, seis foram lidos silenciosamente e usados nas atividades, que foram corrigidas coletivamente, e nove foram lidos em voz alta e seguidos de discussão. Vale mencionar que o momento da correção favoreceu a retomada do texto, mas não a discussão sobre ele.

[...] iniciei a correção do exercício da etapa anterior. Entreguei as folhas de cada um e pedi para que cada aluno lesse a questão e desse a sua resposta. A primeira questão pedia para que os alunos elaborassem perguntas a cada parágrafo do texto "O casarão mal- 
assombrado". Uma das alunas fez a leitura do primeiro parágrafo e disse que sua pergunta era "O que aconteceu ao velho?". Então reli o parágrafo e perguntei se a questão estava de acordo com o que estava escrito. Alguns alunos se manifestaram e disseram que sim, eu complementei dizendo que o parágrafo realmente respondia àquela pergunta.

De acordo com McGee e Schickedanz (2007), há maior desenvolvimento se os alunos participarem ativamente, perguntando, respondendo questões e fazendo predições, em vez de apenas ouvir passivamente a leitura e os comentários do professor. Verificamos que, nas aulas analisadas, a leitura em voz alta seguida de discussão parece ter contribuído para o posicionamento crítico dos alunos diante do texto, uma vez que propuseram finais diferentes para o conto "A tenebrosa noite de tempestade", lido oralmente pela estagiária.

A partir desse momento comecei uma discussão sobre cada texto que havia sido lido. Sobre o primeiro texto questionei-os sobre quais eram os personagens, onde a história acontecia e qual era o evento que mudava o curso da história. Um dos alunos comentou que se ele estivesse na situação do personagem faria diferente do que ele fez, não deixaria a sua filha sozinha. A partir desse comentário outra aluna complementou dizendo que esperaria amanhecer para procurar ajuda, os outros também responderam às perguntas sobre os personagens. Teceram comentários a respeito do desfecho surpreendente da história e deram muitas ideias sobre finais alternativos para história.

Certificamos, assim, que a discussão é bastante importante, porque contribui para a compreensão dos textos lidos. "Na discussão sobre o texto, o 'professor' sumariza o conteúdo, esclarece e prediz" (VANDEWEGHE, 2007, p. 86, tradução nossa), o que fomenta a participação dos alunos, favorecendo que eles respondam perguntas sobre o texto. 


\section{Conclusão}

Ao longo deste artigo, buscamos demonstrar a relação entre as instruções de leitura e o engajamento dos alunos do $9^{\circ}$ do Ensino Fundamental II, de escolas públicas da cidade de Belém, e a quantidade de dúvidas por eles apresentadas. Para isso, recorremos aos estudos sobre concepção e instrução de leitura, desenvolvemos pesquisas qualitativa e documental, bem como realizamos análise de conteúdo.

Com vistas a alcançar o objetivo proposto, buscamos responder a estas perguntas: (i) Que tipos de instrução foram usados para ensinar leitura e com que frequência cada um foi usado?; (ii) Qual é a relação entre o tipo de instrução e o engajamento dos alunos nas atividades?; e (iii) Qual é a relação entre o tipo de instrução e a apresentação de dúvidas pelos alunos?. Quanto à primeira, observamos que foram recorrentes, nas aulas ministradas pela estagiária, as seguintes instruções: leitura em voz alta, leitura silenciosa e discussão oral sobre o texto. Dessas, predominou a leitura em voz alta, sendo frequentemente associada à discussão oral. Em relação à segunda, verificamos que o engajamento dos alunos foi maior quando foram realizadas as instruções leitura em voz alta e discussão oral sobre o texto. Como as discussões foram feitas após os momentos de leitura em voz alta, não foi possível definir qual destas duas estratégias promove mais engajamento, já que estão diretamente relacionadas nas notas de campo analisadas. No tocante à terceira, identificamos que quando predominou a leitura silenciosa os alunos tiveram mais dúvidas sobre o texto lido, o que sugere que eles ainda não tinham desenvolvido a compreensão escrita. Por sua vez, quando a estagiária realizou a leitura em voz alta e a discussão oral, os questionamentos não foram tão frequentes, indicando que eles eram capazes de entender o texto quando essas estratégias de instrução foram usadas.

Comparando esses resultados com as duas hipóteses levantadas durante o tratamento dos dados, refutamos a primeira (Nas aulas em que 
predominou leitura silenciosa, os alunos demonstram mais compreensão do texto), porquanto observamos que os questionamentos a respeito do texto foram mais frequentes quando esse tipo de instrução foi usado, e corroboramos a segunda (Os alunos mostram-se mais engajados nas aulas em que houve discussão oral sobre o texto), uma vez que diferentes alunos participaram da aula, comentando o texto, quando foi proporcionado momentos de discussão sobre o texto.

Nossas observações mostraram que, na comparação com as propostas de leitura silenciosa, nos eventos de leitura em voz alta e discussão oral a respeito do texto, maior é o engajamento dos alunos participantes da pesquisa e menor é a quantidade de dúvidas por eles demonstradas. Não podemos fazer afirmações sobre o nível de proficiência leitora dos alunos que participaram deste estudo. De acordo com os dados analisados, podemos dizer apenas que têm desenvolvido a compreensão oral, já que a oralização foi o meio que contribuiu para que eles demonstrassem mais entendimento sobre o texto.

\section{Referências}

ALVES, M. de F. O ensino de leitura na escola: resultados e perspectivas. Revista Letr@Viv@, v. 11, n. 1, p. 46-54. 2012. Disponível em: $<$ http://periodicos.ufpb.br/index.php/lv/article/view/15313>. Acesso em: 29 mar. 2019.

ANGELO, C. M. P.; MENEGASSI, R. J. M. A leitura compartilhada em sala de apoio. Educação em Revista Belo Horizonte, v.32, n. 3, p. 267-292, jul./set. 2016. Disponível em: <http://www.scielo.br/pdf/edur/v32n3/1982-6621-edur-32-03-00267.pdf >. Acesso em: 29 mar. 2019.

ANTUNES, I. Aula de português: encontro e interação. São Paulo: Parábola, 2003.

BAKHTIN, M. A estética da criação verbal. São Paulo: Martins Fontes, 1997.

BARRETO, R. G.; GUIMARÃES, G. C. O Ensino da leitura no discurso pedagógico contemporâneo. Educação \& Realidade, Porto Alegre, v. 40, n. 2, p. 573-590, abr./jun. 2015. Disponível em: <http://www.scielo.br/pdf/edreal/v40n2/2175-6236-edreal46065.pdf>. Acesso em: 29 mar. 2019. 
BECK, I.; MCKEOWN, M. Text-talk: Capturing the benefits of read-aloud experiences for young children. The Reading Teacher, v. 55, p. 10-20. 2001. Disponível em: <https://www.jstor.org/stable/20205005>. Acesso em: 29 mar. 2019.

CAGLIARI, L. C. Alfabetização \& Linguística. 10 ed. São Paulo: Scipione, 2002.

CAMILO, T. M. Práticas de leitura em sala de aula: modos de ler. Revista Brasileira de Educação e Cultura, n. XII, p. 78-99, jul/dez. 2015. Disponível em: $<$ http://periodicos.cesg.edu.br/index.php/educacaoecultura>. Acesso em: 29 mar. 2019 .

CHARTIER, R. Do códice ao monitor: a trajetória do escrito. Estudos Avançados, São Paulo, v. 8, n. 21, p. 185-199, ago. 1994. Disponível em: <http://www.scielo.br/pdf/ea/v8n21/12.pdf>. Acesso em: 29 mar. 2019.

DANIA, R. C. Processamento em leitura, estrategias metacognitivas e ensino: revisitando os temas. Signo, Santa Cruz do Sul, v.43, n. 77, p. 125-142, maio/ago. 2018 . Disponível

em: $<$ https://online.unisc.br/seer/index.php/signo/article/view/12022>. Acesso em: 29 mar. 2019.

DUKE, N.; MARTIN, N. Best practices in informational text comprehension instruction. In: GAMBRELL, L. B.; MORROW, L. M. Best practices in literacy instruction. 5 ed. New York: Guilford Press, 2015. p. 249-267.

ECROYD, C. A. Motivating students through reading aloud. English Journal, v. 80, n. 6, p.76-78, out. 1991.

FANG, Z. Approaches to developing content area literacies: a synthesis and a critique. Journal of Adolescent \& Adult Literacy, v. 56, n. 2, p. 103-108. 2012. Disponível em: <https://ila.onlinelibrary.wiley.com/doi/full/10.1002/JAAL.00110>. Acesso em: 29 mar. 2019.

FISHER, D. et al. Interactive read-alouds: is there a common set of implementation practices? The Reading Teacher, v. 58, n. 1, p. 8-17, set. 2004. Disponível em: <https://www.jstor.org/stable/20205442>. Acesso em: 29 mar. 2019.

FISHER, D; FREY, N. Best practices in adolescent literacy instruction. In: GAMBRELL, L. B.; MORROW, L. M. Best practices in literacy instruction. 5 ed. New York: Guilford Press, 2015. p. 149-166.

FOUNTAS, I.; PINNELL, G. S. Teaching for comprehending and fluency. Portsmouth, NH: Heinemann, 2006.

FUZA, A. F.; OHUSCHI, M. C. G.; MENEGASSI, R. J. Concepções de linguagem e o ensino da leitura em língua materna. Linguagem \& Ensino, Pelotas, v. 14, n. 2, p. 479-501, jul./dez. 2011. Disponível em: <http://www.rle.ucpel.tche.br/index.php/rle/article/view/36>. Acesso em: 29 mar. 2019 . 
GAMBRELL, L. B.; MORROW, L. M. Best practices in literacy instruction. 5 ed. New York: The Guilford Press, 2015.

GODOY, A. S. Pesquisa qualitativa: tipos fundamentais. Revista de Administração de Empresas, v. 35, n. 3, p. 20-29. 1995. Disponível em: $<$ http://www.scielo.br/scielo.php?script=sci_arttext\&pid=S0034-

75901995000300004>. Acesso em: 29 mar. 2019.

GOLDMAN, S.; SNOW, C.; VAUGHN, S. Common themes in teaching reading for understanding: lessons from three projects. Journal of Adolescent \& Adult Literacy, v. 60, n. 3, p. 255-264. 2016. Disponível em: <https://doi.org/10.1002/jaal.586>. Acesso em: 29 mar. 2019.

GOMES, R. Análise de dados em pesquisa qualitativa. In: MINAYO, C. (Org.). Pesquisa social: teoria, método e criatividade. Rio de Janeiro: Vozes, 1994. p. 67-80.

GOMES, S. dos S. Avaliação das capacidades de leitura. Educar em Revista, Curitiba, n. 63, p. 221-236, jan./mar. 2017 Disponível em: $<$ https://revistas.ufpr.br/educar/article/view/46325/0>. Acesso em: 29 mar. 2019.

HELDER, R. Como fazer análise documental. Porto: Universidade de Algarve, 2006.

HOLMES, B. C. The effect of four different modes of reading on comprehension. Reading Research Quarterly, v. 20, n. 5, p. 575-585. 1985. Disponível em: <https://www.jstor.org/stable/747944>. Acesso em: 29 mar. 2019.

KINTSCH, W.; KINTSCH, E. Comprehension. In: PARIS, S. G.; STAHL, S. A. (Org.). Children's reading comprehension and assessment.New Jersey: Lawrence, 2005. p. 71-92.

KLEIMAN, Â. Oficina de leitura: teoria e prática. São Paulo: Pontes, 1992.

KLESIUS, J. P.; GRIFFITH, P. L. Interactive storybook reading for at-risk learners. The Reading Teacher, v. 49, p. 552-560. 1996.

KOCH, I. V.; ELIAS, V. M. Ler e compreender os sentidos do texto. São Paulo: Contexto, 2014.

LUCAN, L.; HAPGOOD, S.; PALINCSAR, A. S. Teachers' specialized knowledge for supporting student comprehension in text-based discussions. The Elementary School Journal, v. 112, n. 1, p. 61-82, set. 2011. Disponível em: <https://www.jstor.org/stable/10.1086/660689>. Acesso em 29 mar. 2019.

MARINAK, B. A.; GAMBRELL, L. B. Intrinsic motivation and rewards: what sustains young children's engagement with text? Literacy Research and Instruction, v. $47, \quad$ n. $1, \quad$ p. 9-26. 2008. Disponível em: <https://doi.org/10.1080/19388070701749546>. Acesso em: 29 mar. 2019.

McGEE, L. M.; SCHICKEDANZ, J. A. Repeated interactive read-alouds in preschool and kindergarten. The Reading Teacher, v. 60, n. 8, p. 742-751, maio. 2007. Disponível em: <https://www.jstor.org/stable/20204534>. Acesso em: 29 mar. 2009. 
McELHONE, D. Tell us more: Reading comprehension, engagement, and conceptual press discourse. Reading Psychology, v. 33, n. 6, p. 525-561. 2012. Disponível em: < https://doi.org/10.1080/02702711.2011.561655>. Acesso em: 29 mar. 2019.

MEDINA, M. B.; PRADES, D. A formação de mediadores: por que e para que promover a leitura? In: PRADES, D.; LEITE, P. B. P. (Org.). A formação dos mediadores. São Paulo: Livros da Matriz, 2015. p. 16-28.

MENEGASSI, R. J. Leitura e ensino. 2 ed. Maringá: Editora da Universidade de Maringá, 2010.

MERCER, N.; DAWES, L. The value of exploratory talk. In: MERCER, N. HODGKINSON, S. (Org.). Exploring talk in school. Thousand Oaks, CA: Sage, 2008. p. 55-72.

MORRISON, V.; WLODARCZYK. Revisiting read-aloud: instructional strategies that encourage students' engagement with texts. The Reading Teacher, v. 63, n. 2, p. 110-118, out. 2009. Disponível em: <https://doi.org/10.1598/RT.63.2.2>. Acesso em: 29 mar. 2019.

MURPHY, P. K. et al. Examining the effects of classroom discussion on students' comprehension of text: a meta-analysis. Journal of Educational Psychology, v. 101, n. $3, \quad$ p.740-764. 2009. Disponível em: <http://qualitytalk.org/pdf/Murphy_et_al_2009.pdf>. Acesso em: 29 mar. 2019.

OLIVEIRA, A. C. de. A leitura oral na escola do mundo contemporâneo: uma prática marginal ou inexistente? Revista Brasileira de Linguística Aplicada, v.3, n .l, p. 133184. 2003. Disponível em: <http://www.scielo.br/pdf/rbla/v3n1/09.pdf>. Acesso em: 29 mar. 2019.

PÁDUA, E. M. M. de. Análise de conteúdo, análise de discurso: questões teóricometodológicas. Revista de Educação. Campinas, n. 13, p. 21-30. 2002. Disponível em: $<$ https://docplayer.com.br/15960170-Analise-de-conteudo-analise-de-discursoquestoes-teorico-metodologicas.html>. Acesso em: 29 mar. 2019.

PANICHELLA, F. C. Concepções de leitura: diferentes perspectivas para a linguagem e o texto em sala de aula. Revista Leitura, v. 2, n. 56, p. 42-59, jul/dez. $2015 . \quad$ Disponível em: $<$ http://www.seer.ufal.br/index.php/revistaleitura/article/view/2204>. Acesso em: 29 mar. 2019.

PEREIRA, V. W.; SANTOS, T. V. dos. Estratégia de leitura de predição na escola: uso e consciência linguística no seu uso. Linguagem em (Dis)curso. Tubarão, v. 17, n. 3, p. 361-380, set./dez. 2017. Disponível em: <http://www.scielo.br/pdf/ld/v17n3/15187632-ld-17-03-00361.pdf>. Acesso em: 29 mar. 2019.

PIERCE, K.M.; GILLES, C. From exploratory talk to critical conversations. In: MERCER, N.; HODGKINSON, S. (Org.). Exploring talk in school. Thousand Oaks, CA: Sage, 2008. p. 37-54. 
RASINSKI, T.; PADAK, N. Effective reading strategies: teaching children who find reading difficult. 2 ed. Ohio: Merrill-Prentice Hall, 2000.

RODRIGUES, N. C. Leitura nos ensinos fundamental e médio: reflexões sobre algumas práticas. Linguagem em (Dis)curso. Tubarão, v. 7, n. 2, p. 215-240, mai./ago. $2007 . \quad$ Disponível em: $<$ http://linguagem.unisul.br/paginas/ensino/pos/linguagem/linguagem-emdiscurso/0702/070203.pdf>. Acesso em: 29 mar. 2019.

SHANAHAN, T.; SHANAHAN, C. Teaching disciplinary literacy to adolescentes: rethinking content-area literacy. Harvard Educational Review, v. 78, n. 1, p. 40-59. 2008.

SILVA, E. T. da. Concepções de Leitura e suas consequências no ensino. Perspectiva, Florianópolis, v.17, n. 31, p. 11-19, jan./jun., 1999. Disponível em: $<$ https://periodicos.ufsc.br/index.php/perspectiva/article/viewFile/10708/10213>.

Acesso em: 29 mar. 2019.

SILVA, L. L. M. da. Pra Que a Gente Lê? Perspectiva, Florianópolls, v. 1, n. 4, 15-26, jan./dez. 1985.

Disponível

em: $<$ https://periodicos.ufsc.br/index.php/perspectiva/article/viewFile/8827/8166>.

Acesso em: 29 mar. 2019.

SMITH, F. Compreendendo a leitura: uma análise psicolinguística da leitura e do aprender a ler. Porto Alegre: Artes Médicas, 1989.

SOLÉ, I. Estratégias de leitura. 6. ed. Porto Alegre: Editora Artmed, 1998.

SOTER, A. O. et al. What the discourse tells us: talk and indicators of high-level comprehension. International Journal of Educational Research, v. 47, n. 6, p. 372 391. 2008. Disponível em: <https://doi.org/10.1016/j.ijer.2009.01.001>. Acesso em: 29 mar. 2019.

TASSONI, E. C. M.; RIBEIRO, R. S. As práticas de leitura e escrita de alunos de um $2^{\circ}$ ano do ensino médio. Linguagem em (Dis)curso. Tubarão, v. 13, n. 1, p. 157-186, jan./abr. 2013.2 Disponível em: $<$ http://www.portaldeperiodicos.unisul.br/index.php/Linguagem_Discurso/article/vi ew/1498>. Acesso em: 29 mar. 2019.

VANDEWEGHE, R. What kinds of classroom discussion promote reading comprehension? English Journal, v. 96, n. 3, p. 86-91, jan. 2007. 